\title{
Deposition of mimics of planktonic invertebrate larvae on simple and complex substrata in flume flows
}

\author{
Yves Grégoire $^{1}$, Edwin Bourget $^{1, *}{ }^{,}$Jean-Louis Verrette ${ }^{2}$ \\ ${ }^{1}$ GIROQ, Département de Biologie, Université Laval, Québec, Québec, Canada G1K 7P4 \\ ${ }^{2}$ Département de Génie Civil, Université Laval, Québec, Québec, Canada G1K 7P4
}

\begin{abstract}
The purpose of this study was to compare the distribution of inert particles on polyvinylchloride (PVC) panels with earlier results from field studies. The panels were prepared in order to test heterogeneity (crevices similar in shape, but differing in size) and complexity (combination of crevices of different sizes) effects. The experiments were carried out using PVC particles and preserved Placopecten magellanicus larvae in a flume under controlled flow conditions (mean velocities of 3,5 and $10 \mathrm{~cm} \mathrm{~s}^{-1}$ ) and using silicon-coated panels. The heterogeneous panels had different combinations of flat surfaces and 1,10 and $100 \mathrm{~mm}$ crevices. The density of particles per unit surface area adhering to the panels was higher at 3 and $5 \mathrm{~cm} \mathrm{~s}^{-1}$ than at $10 \mathrm{~cm} \mathrm{~s}^{-1}$ for all experiments. The density of adhering particles decreased with increasing panel complexity. Within panels with only $1 \mathrm{~mm}$ crevices, the density of particles was significantly higher inside the crevices than on smooth surfaces. However the density of particles was significantly lower in 10 and $100 \mathrm{~mm}$ crevices than on adjacent flat surfaces within panels with only 10 and $100 \mathrm{~mm}$ crevices, respectively. Furthermore, the 1 and $10 \mathrm{~mm}$ crevices nested inside $100 \mathrm{~mm}$ crevices collected fewer particles than those outside $100 \mathrm{~mm}$ crevices within panels with many scales of crevices. The patterns of distribution for dead larvae on heterogeneous panels in the flume corresponded to those of the inert PVC particles. However, the distribution patterns of inert particles in the flume did not correspond to those of living bivalve spat observed in an earlier field study. This suggests that larval behaviour contributed to the selection of settlement location for these bivalve larvae, though flume hydrodynamical conditions may differ from those in the field. The results also indicate that the hydrodynamic processes affecting settlement on heterogeneous substrates are scale-dependent and that processes occurring at scales of 10 and $100 \mathrm{~mm}$ influence processes occurring at smaller, $1 \mathrm{~mm}$, scales.
\end{abstract}

KEY WORDS: Planktonic invertebrate larvae Substratum heterogenity Substratum complexity Flume Micro-habitat selection

\section{INTRODUCTION}

The distribution patterns of many sessile invertebrates are influenced by settlement site selection (Bourget 1988) which is evident from the aggregation of individuals on a substratum (Jensen \& Morse 1984) These patterns reflect the various factors that influence sessile invertebrate larval settlement. Factors which play a role in larval settlement include: light, gravity, hydrostatic pressure (Crisp 1974), larval concentration (Gaines et al. 1985), bacterial films (Mihm et al. 1981.

\footnotetext{
- Corresponding author.

E-mail: edwin.bourget@giroq.ulaval.ca
}

Kirchmann et al. 1982), organic matter (Crisp 1974), inorganic matter (Mullineaux \& Butman 1990), substrate type (Rittschof et al. 1984), conspecifics (Wethey 1984, Chabot \& Bourget 1988), and hydrodynamic processes (Havenhand \& Svane 1991, Pawlik \& Butman 1993, Mullineaux \& Garland 1993). Substratum heterogeneity plays an important role, particularly for cirripede settlement (Le Tourneux \& Bourget 1988, Chabot \& Bourget 1988, Bourget et al. 1994). However, the distribution of settlers and some aggregate patterns may be limited by substrate availability.

There is evidence of larval preference under laboratory conditions; cirripede larvae prefer pitted over smooth surfaces (Crisp 1974). The interaction between 
hydrodynamic processes and substratum heterogeneity at scales $<10 \mathrm{~cm}$ on larval settlement has been the focus of several studies. Snelgrove et al. (1993) showed that circular depressions $(3.8 \mathrm{~cm}$ in diameter) increased the number of bivalve and polychaete larvae settling on a given substratum. The effect of depressions appeared to be scale-dependent with larger depressions enhancing settlement.

More recently, Bourget et al. (1994) carried out a field study using panels with many scales of heterogeneity (crevices of similar shape but of different sizes) and complexity (combinations of different scales of heterogeneity). The 1 and $10 \mathrm{~mm}$ crevices collected higher densities of larvae of different bivalve species compared to larger crevices, but for more complex panels only $1 \mathrm{~mm}$ crevices showed enhanced settlement. The 'influence of heterogeneity' on settlement comprises several factors, including active larval behaviour during settlement and local hydrodynamic influences near or within crevices and adjacent surfaces (Bourget et al. 1994). However, the hydrodynamic influence was not explicitly investigated in Bourget et al.'s study.

Within the bottom boundary layer, flow velocity is reduced and competent larvae of some species may swim freely while selecting a settlement site (Pawlik \& Butman 1993). For other species, the first contact with the substratum is controlled by hydrodynamic processes (Mullineaux \& Butman 1990, 1991, Harvey et al. 1995).

Enhanced turbulence and advection towards the substratum should increase the contact rate of particles with the surface. Whereas reduced shear stress should increase particle residence time on the surface, for larvae that are passively transported by currents, increased contact or retention on the surface would occur under conditions of any combination of high advection towards the substratum, enhanced turbulence or reduced shear stress (see Mulineaux \& Garland 1993)

Studies of settlement in relation to small-scale hydrodynamic processes have been carried out with smooth and more recently on heterogeneous surfaces (see Snelgrove et al. 1993). However, natural marine topography is complex; thus, settlement needs to be understood in reference to both these parameters. In the present study we examined the influence of substratum heterogeneity and complexity on the settlement of inert particles using panels of known heterogeneity and complexity. These panels have previously been used in field settlement studies (Bourget et al. 1994, Lemire \& Bourget 1996 in this issue). We used polyvinylchloride (PVC) particles and dead larvae as models to eliminate the effect of active larval behaviour The hypotheses tested were (1) that larvae and inert particles settle more abundantly on substrata of increasing heterogeneity and complexity and (2) that current velocity influences the density and distribution of inert particles.

\section{MATERIAL AND METHODS}

Flume design. Passive settlement experiments were carried out using a $0.6 \times 0.6 \times 13 \mathrm{~m}$ (width $\times$ height $x$ length) single-passage flume at the Université Laval Département de génie civil. Details of the flume are described in Harvey et al. (1995). A $0.6 \times 8.9 \mathrm{~m}$ false. bottom was installed and tightly fixed $12 \mathrm{~cm}$ above the bottom of the flume. This false bottom was made of 4 PVC sheets $(1.25 \mathrm{~cm}$ thick) of equal length. The furthest upstream and downstream sheets were slightly inclined, $-4^{\circ}$, and the 2 central sheets were horizontal. The 2 central parts were placed $0.3 \mathrm{~m}$ apart. This gap allowed the installation of the $0.3 \times 0.3 \mathrm{~m}$ interchangeable experimental panels which, when fixed in the center, were flush with the false bottom (see 'Experimental panels' section). Water temperature was maintained at $10^{\circ} \mathrm{C}$ and salinity at $25 \%$. The working section, $3.6 \mathrm{~m}$ downstream of the entrance of the flume, was characterized by a uni-directional average flow. Three flow velocities, 3,5 and $10 \mathrm{~cm} \mathrm{~s}^{-1}$, calculated as the vertically integrated mean velocity over the central $2.75 \mathrm{~m}$ section of the flume were used for the experiments. In these experiments, we were testing a generic case for a developing boundary layer over panel surfaces in slow flows and not trying to mimic a particular field environment.

The evaluation of Reynolds number indicates a turbulent flow. This was also confirmed by visual observation. The experiments conducted with low velocities were at low turbulent regime $\left(\operatorname{Re} \approx 5 \times 10^{3}\right)$.

Boundary shear velocity ( $u .$, Schlichting 1962) near the wall was estimated using:

$$
u \cdot=u(f / 8)^{0.5}
$$

where $u$ is the velocity and $f$ is the friction factor (related to Darcy-Weisbach equation); the equation assumes an equilibrium boundary layer, a condition which may not entirely have been met. The estimated values of $u$. for velocities of 3,5 and $10 \mathrm{~cm} \mathrm{~s}^{-1}$ were 0.2 , 0.3 and $0.6 \mathrm{~cm} \mathrm{~s}^{-1}$ respectively.

Experimental panels. The term 'scale of heterogeneity' has been defined as the size of equilateral grooves with sides of 1, 10 and $100 \mathrm{~mm}$, on PVC panels (Bourget et al. 1994). 'Complexity', 1st to 4 th order, refers to the number of scales of heterogeneity represented on a given panel. The crevices were oriented normal to the flow.

A total of 8 different panel types were used (Fig. 1) corresponding to those used in field studies by Bour- 


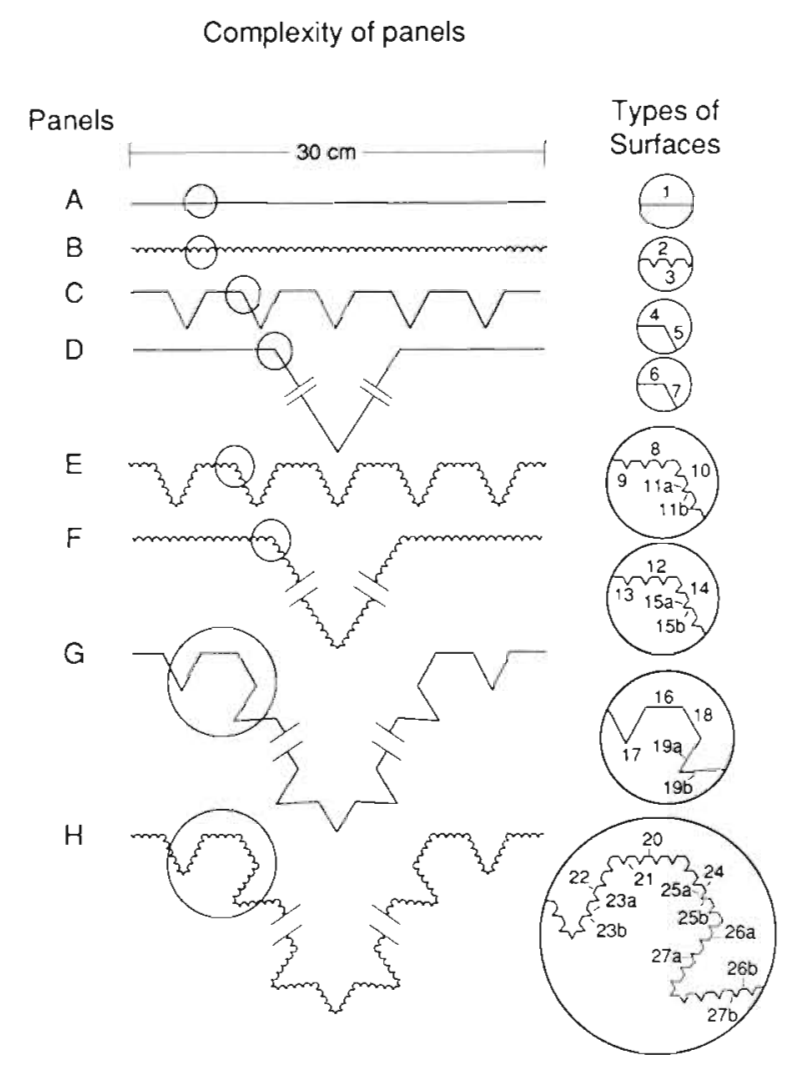

Fig. 1. Types of panels and surfaces used during the experiments with inert particles. Crevice angle is illustrated in Fig. 2

get et al. (1994) and Lemire \& Bourget (1996). These included. one of 1 st order complexity, smooth, panel $A_{i}$ three of 2 nd order complexity, smooth + crevice sizes, $0+1,0+10$ and $0+100 \mathrm{~mm}$ for panels $\mathrm{B}, \mathrm{C}$ and $D$, respectively; three of $3 \mathrm{rd}$ order complexity, smooth + nested crevice size + crevice sizes, $0+1+10,0+1$ $+100,0+10+100 \mathrm{~mm}$ for panels $\mathrm{E}, \mathrm{F}$ and $\mathrm{G}$, respectively and one of 4 th order complexity, smooth +2 orders of nested crevices + crevice size: $0+1+10+$ $100 \mathrm{~mm}$, panel $\mathrm{H}$. Thus, panels of $1 \mathrm{st}, 2 \mathrm{nd}, 3 \mathrm{rd}$ and 4 th order complexity displayed 1, 2, 5 and 12 different types of surfaces, respectively (Fig 1). Panels of 3 rd and 4 th order complexity contained crevices with different orientations: $+30^{\circ}$ and $-30^{\circ}$ to horizontal and $90^{\circ}$ vertical crevices, whereas panels of the 1 st and 2nd order complexity had vertical crevices only (Fig. 2).

Classification of rough or smooth walls is made by comparison of the reduced thickness of the laminar sublayer expressed by $\delta \cdot u . / v \approx 12$ with the average height of roughness expressed under the reduced form $k_{\mathrm{s}} u . / v\left(\delta^{\prime}\right.$ is the absolute thickness of the laminar sublayer and $k_{\mathrm{s}}$ is the absolute height of roughness). When the height of roughness is smaller $(-5)$ than the

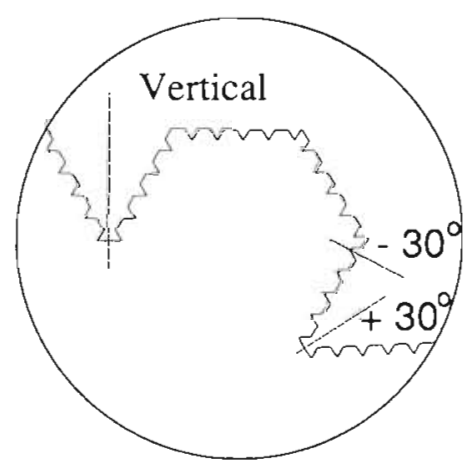

Fig. 2. Crevice angles observed on the panels. Fig. 1 presents an overall view of panels

thickness of the laminar sublayer, the wall is said to be hydrodynamically smooth. On the contrary, when the height of the roughness is much larger $(\sim 100)$ than the thickness of the laminar sublayer, the wall is said to be hydrodynamically rough. Obviously, the transition is not sharp and there is a transition zone $(5<$ $k_{\mathrm{s}} u . / \mathrm{v}<70$ ) where the wall is said to be semi-rough. In our experiments, it is rather difficult to evaluate the value of the average roughness heights since we have few repetitions and the roughness (crevices) only spans a small proportion of the bottom. The 1 and $10 \mathrm{~mm}$ crevices are repeated many times, so we can determine the average roughness heights for these crevices. The $100 \mathrm{~mm}$ crevices occur only once per panel, so it is difficult to determine any realistic average height of the roughness elements. Table 1 gives the average roughness heights for the 1 and $10 \mathrm{~mm}$ crevices for the 3 flow velocities.

Inert particles. PVC microparticles (PVC 'GEON 103EPF76', BF Goodrich, USA; density $=1400 \mathrm{~kg} \mathrm{~m}^{-3}$ ) between 150 and $250 \mu \mathrm{m}$, the size of larvae of many invertebrate species, were obtained using calibrated sieves. The fall velocity $\left(-4.18 \mathrm{~mm} \mathrm{~s}{ }^{1}\right)$ of the particles was assumed to be the same as that of similar PVC particles used by Lindegarth et al. (1991). The particles were stained using a thin fluorescent dye ('DAY-GLO

Table 1 Average roughness heights $\left(k_{s} u . / \nu\right)$ for the different combinations of crevice sizes and flow velocities

\begin{tabular}{|lcc|}
\hline & \multicolumn{3}{c|}{ Crevice size } \\
Flow velocity & $1 \mathrm{~mm}$ & $10 \mathrm{~mm}$ \\
& $\begin{array}{c}\text { Average crevice depth }\left(k_{\mathrm{s}}\right) \\
0.86 \mathrm{~mm}\end{array}$ & $8.66 \mathrm{~mm}$ \\
\hline $3 \mathrm{~cm} \mathrm{~s}^{-1}$ & 1.7 & 17.3 \\
$5 \mathrm{~cm} \mathrm{~s}^{-1}$ & 2.6 & 26.0 \\
$10 \mathrm{~cm} \mathrm{~s}^{-1}$ & 5.2 & 52.0 \\
\hline
\end{tabular}


No. A-17', Color Corp.) and counted on the substratum using a UV lamp (Lindegarth et al. 1991). The panels were covered with a thin uniform layer of silicone High-Vacuum Grease (Dow Corning, USA) to ensure particle adhesion at first contact (Walters 1992, Harvey et al. 1995)

Experimental procedure. For each trial, experimental panels were installed in the dry flume. The flume was then filled with water $40 \mathrm{~cm}$ above the central portion of the false-bottom. The flow was started and the experimental panel was exposed to particles for $10 \mathrm{~min}$. The particles were maintained in a $10 \mathrm{~g} \mathrm{l}^{-1}$ solution and continually mixed by a rotor at $5000 \mathrm{rpm}$. A uniform distribution of particles was achieved by pumping a constant rate of this mixture $\left(3.5 \mathrm{ml} \mathrm{min}^{-1}\right)$ through a series of 16 evenly spaced releasing tygon tubes placed $4 \mathrm{~m}$ upstream from the target panels (Harvey et al. 1995). The flow was shut off and the panel removed. Particles that had settled on the false bottom of the flume during the experiment were removed with a shop-vac vacuum cleaner and a new panel installed for the next run. The order in which the experimental panels were tested and the flow velocity were randomly determined at the start of each day. In total, 5 replicates for each panel type $\times$ water velocity combination were run.

Whether deviations from 1-dimensionality in the flume flow field significantly affected distributions of particles within the test section was examined by comparing the density of particles across the panels for both panels $A$ and $C$ at flow velocities of 3,5 and $10 \mathrm{~cm} \mathrm{~s}^{-1}$. The number of particles observed in ten $1 \times$ $200 \mathrm{~mm}$ quadrats (oriented across the crevices parallel to the flow) was determined for each of the six $5 \mathrm{~cm}$ wide zones (oriented parallel to the flow) and covered the $30 \mathrm{~cm}$ width of each panel. These data were compared by ANOVA. Distribution of particles across the flume showed significant differences among zones but close examination of the results showed no systematic bias among trials $(n=5)$ within or among current velocities. When comparisons were made among 4 successive sections of $5 \times 20 \mathrm{~cm}$ in the downstream direction along the surface of smooth panels (type $A$, 5 replicates), no significant differences were observed among sections, indicating uniform distribution of particles in the downstream direction. Vertical rods inserted into smooth panels (type A) were used to verify the cross-stream distribution of particles in the 1st $\mathrm{cm}$ of water above the panel. The rods $10.3 \mathrm{~cm}$ in diameter, $2 \mathrm{~cm}$ high) were evenly spaced $(3 \mathrm{~cm}$ apart) across the central part ( $30 \mathrm{~cm}$ wide) of the flume. No significant differences in particle abundance were observed among rods which had been inserted to verify crossstream particle distribution at flow velocities of 3 and $10 \mathrm{~cm} \mathrm{~s}^{-1}$; only 1 rod collected more than the others at
$5 \mathrm{~cm} \mathrm{~s}^{-1}$, but this rod was outside the section where samples were taken for the heterogeneity and complexity experiments.

Sampling. Two scales of observation were used to investigate particle distribution on the panels: (1) the scale of the entire panel and (2) the scale of a crevice. either 1, 10 or $100 \mathrm{~mm}$. Particle abundance was determined first for the entire panel and second for each surface type within the panel. To minimize contour (border of panels) effects (Brault \& Bourget 1985), only the central zone $(200 \times 200 \mathrm{~mm})$ of the panels was sampled.

We sampled the panels following a hierarchical method such that $20 \%$ of the total surface area (TSA) of each surface was sampled. Randomly chosen $1 \times$ $200 \mathrm{~mm}$ quadrats parallel to the crevices (i.e. normal to the flow) allowed a minimum of 5 samples to be taken for any given surface type. Each type of panel was tested 5 times. The increase in TSA for panels of 2nd, 3rd and 4th order complexity increased by factors of $1.5,2.25$ and 3.375 , respectively, over that of the smooth panel (1st order complexity). Since each $200 \mathrm{~mm}$ length quadrat covered the entire width of the experimental area on the panels, this compensated for any lateral variation in particle density.

Statistical analyses. The number of settled particles was compared among types of panels using particle density (number of particles $\mathrm{cm}^{-2}$ ) for each panel. Density data were analysed using the following model for a 2-way nested ANOVA:

$$
\begin{aligned}
y= & \mu+\text { Velocity }+ \text { Day }(\text { Velocity })+ \\
& \text { Panel }+ \text { Velocity } \times \text { Panel }+ \text { Error }
\end{aligned}
$$

where $\mu$ is a constant, Velocity is the mean flow velocity $\left(3,5\right.$ or $\left.10 \mathrm{~cm} \mathrm{~s}^{-1}\right)$, Day is the day of the experiments $(1,2,3, \ldots 15)$ which is nested into the Velocity term and Panel refers to the type of panels used $(A, B, C, \ldots H)$. There were 5 replicates for each condition (see Kirk 1982). The Day (Velocity) term was calculated to be used as an error term for Velocity. When the ANOVA was significant, LS Means multiple comparisons were used in order to find out which means differed (Milliken \& Johnson 1992). Day (Velocity) is not meaningful for our interpretation, other than serving as an error term, and will not be considered further.

Density data among surface types were compared for each type of panel using the following nested crossed ANOVA model:

$$
\begin{aligned}
y= & \mu+\text { Velocity }+ \text { Day }(\text { Velocity })+\text { Surface }+ \\
& \text { Velocity } \times \text { Surface }+ \text { Day }(\text { Velocity }) \times \text { Surface } \\
& + \text { Error }
\end{aligned}
$$

where $\mu$ is a constant, Velocity is as defined previously, Day is the day of the experiments $(1,2,3, \ldots$ 15) which is nested into the Velocity term, and Surface refers to the type of surfaces used (see Fig. 1). Day(Velocity) 
was calculated to serve as error term for Velocity and Surface, and Day (Velocity) $\times$ Surface was calculated to serve as error term for Velocity $\times$ Surface, and will not be considered further. There were no significant interactions between velocity and types of panels (Surfacex Velocity), hence these interactions will not be considered further.

The statistical analyses were carried out on the details of surface orientation. LS Means tests revealed that the 2 sides of a crevice were rarely significantly different, irrespective of the size of the crevice. The axes of the crevices were oriented with 3 distinct possibilities: the axis could be vertical $+30^{\circ}$ to horizontal or $-30^{\circ}$ to horizontal (see Fig. 2). When the axis of the crevice was vertical or $-30^{\circ}$ to horizontal, densities of particles on both sides of the crevices were not significantly different from one another. However, when the axis of the crevice was $+30^{\circ}$ to horizontal, densities of particles on both sides of the crevices were significantly different. Thus, we separately considered the 2 sides of a crevice only when the axis of the crevice was $+30^{\circ}$ to horizontal. We ran the ANOVAs and the LS Means tests over again with the data containing less types of surfaces. The results from the pooled approach are shown in the next section instead of the results with the original unpooled approach. One ANOVA was carried out for each type of panel instead of one ANOVA for all types of panels because of the model complexity. All analyses were carried out on data transformed to the two-third power $\left(x^{0.66}\right)$ to reduce heteroscedascity (Montgomery 1991). Sign tests for matched pairs (Conover 1980) were used to examine the null hypothesis of uniform distribution of particles, regardless of the presence of crevices.

Experiments with preserved larvae. Experiments were conducted using preserved Placopecten magellanicus larvae to determine if distribution patterns were similar to the PVC particles on the panels. Because of the few larvae available, this experiment was performed using only panel $\mathrm{H}$. Panel $\mathrm{H}$ was selected because it contained all heterogeneity types (4th order complexity). Data analyses were performed using an ANOVA model similar to that used for PVC particles. The distribution of $P$. magellanicus larvae was compared to that of PVC particles by Kendall's coefficient of concordance (Conover 1980)

\section{RESULTS}

\section{Comparisons among types of panels}

There were significant Panel and Velocity effects on particle density (Table 2a). The density of particles decreased significantly with increasing complexity, with panel types $\mathrm{A}$ and $\mathrm{B}$ consistently collecting more and $\mathrm{G}$ and $\mathrm{H}$ fewer particles $\mathrm{cm}^{-2}$ for each flow velocity (Table 3). For a given level of complexity, panels with $1 \mathrm{~mm}$ crevices tended to collect the highest density (Table 3), but this effect was never significant. The density of particles collected at 3 and $5 \mathrm{~cm} \mathrm{~s}^{-1}$ was significantly higher than for $10 \mathrm{~cm} \mathrm{~s}^{-1}$ for all experiments (Fig. 3). The ANOVA showed that the Velocity $\times$ Panel term was not significant (Table 2a).

\section{Comparisons among types of surfaces within panels at all scales}

Significant surface effects were observed for all types of panels (Table $2 b$ to i). For panels with 2nd order complexity, particle density was higher inside $1 \mathrm{~mm}$ crevices than on adjacent flat surfaces of panel type $\mathrm{B}$, whereas the converse was true for 10 and $100 \mathrm{~mm}$ crevices, panel types $\mathrm{C}$ and $\mathrm{D}$, respectively (Table 4). Panels with 3 rd and 4 th order complexity showed variable and complex effects.

Nesting of crevices resulted in the axis of the smallest crevices being inclined at $-30^{\circ}$ instead of vertical $\left(90^{\circ}\right)$. In this case, the density of particles on the lower side (closest to the horizontal) was consistently higher than that on the upper side (Tables 4 \& 5). For the panel with 4 th order complexity (panel $\mathrm{H}$ ), the scale of heterogeneity also influenced the magnitude of differences between the 2 sides of the $+30^{\circ}$ crevices. For $1 \mathrm{~mm}$ crevices the 2 sides had high but different densities of particles (Fig. 4, panel H, types of surface 25a and $25 \mathrm{~b}$ ) whereas the lower side of the $10 \mathrm{~mm}$ crevices

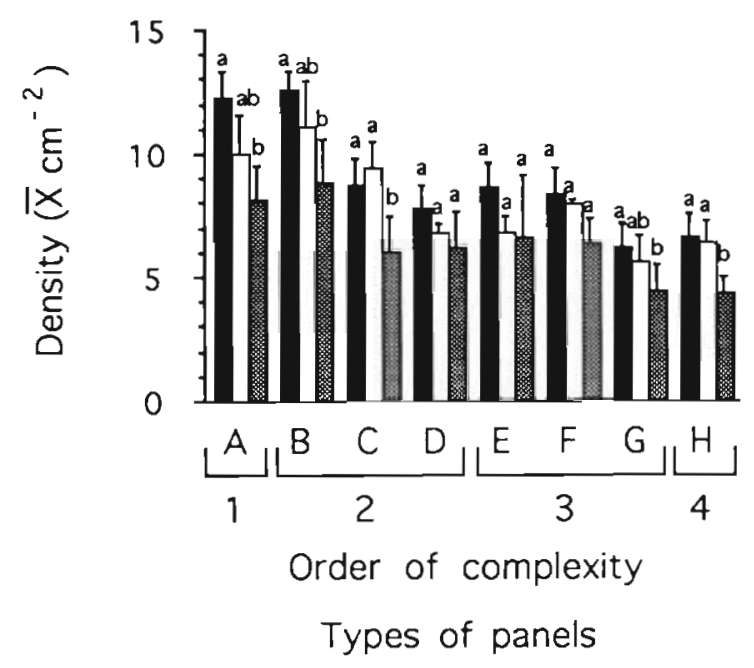

Fig. 3. Density of inert partucies ( $\pm S E$ ) on aij rypes oí paneis. Flow velocity: $\square=0.03, \square=0.05, \square=0.10 \mathrm{~m} \mathrm{~s}^{-1}$, respectively. Letters above histograms indicate means that are not signiflcantly different between flow velocities 
Table 2. Crossed nested ANOVAs showing (a) the effects of Velocity, Day (Velocity) and types of Panels on particle density, (b to i) the effects of Velocity, Day (Velocity) and types of Surfaces on number of particles for every type of panels, and (j) on total number of preserved Placopecten magellanicus larvae on panel $\mathrm{H}$. The effects of Velocity were evaluated using Day (Velocity) as an error term. The effects of Surface and Surface $\times$ Velocity were evaluated using Surface $\times$ Day (Velocity) as an error term. $(\bullet)$ Not computable since only 1 type of surface was present

\begin{tabular}{|c|c|c|c|c|c|c|c|c|c|}
\hline Source of variation & df & $\begin{array}{l}\text { Sum of } \\
\text { squares }\end{array}$ & F-value & $\mathrm{p}$ & Source of variation & $d t$ & $\begin{array}{l}\text { Sum of } \\
\text { squares }\end{array}$ & F-value & $\mathrm{p}$ \\
\hline \multicolumn{5}{|l|}{ (a) Among panels } & \multicolumn{5}{|l|}{ (i) Panel E } \\
\hline Velocity & 2 & 8.69 & 12.52 & 0.0012 & Velocity & 2 & 358.75 & 2.74 & 0.1049 \\
\hline Day (Velocity) & 12 & 4.16 & 4.74 & 0.0001 & Day (Velocity) & 12 & 775.54 & 50.81 & 0.0001 \\
\hline Panel & 7 & 33.38 & 65.14 & 0.0001 & Surface & 4 & 1948.17 & 62.17 & 0.0001 \\
\hline Panel $\times$ Velocity & 14 & 1.85 & 1.80 & 0.0514 & Surface $\times$ Velocity & 8 & 89.02 & 1.45 & 0.2021 \\
\hline Error & 84 & 6.15 & & & Surface $\times$ Day (Velocity $)$ & 48 & 369.29 & 6.05 & 0.0001 \\
\hline Corrected total & 119 & & & & Error & 1275 & 1624.71 & & \\
\hline \multicolumn{5}{|l|}{ (b) Panel A } & \multirow{2}{*}{\multicolumn{5}{|c|}{ (g) Panel F }} \\
\hline Velocity & 2 & 391.36 & 11.44 & 0.0017 & & & & & \\
\hline Day (Velocity) & 12 & 205.22 & 16.56 & 0.0001 & Velocity & 2 & 316.64 & 7.51 & 0.0077 \\
\hline Surface & 0 & 0.00 & $\bullet$ & $\bullet$ & Day (Velocity) & 12 & 262.97 & 17.02 & 0.0001 \\
\hline Surface $\times$ Velocity & 0 & 0.00 & - & - & Surface & 4 & 2862.98 & 92.36 & 0.0001 \\
\hline Surface $\times$ Day $($ Velocity $)$ & 0 & 0.00 & - & - & Surface $\times$ Velocity & 8 & 91.99 & 1.48 & 0.1881 \\
\hline Error & 585 & 604.27 & & & Surface $\times$ Day (Velocity) & 48 & 371.99 & 6.26 & 0.0001 \\
\hline Corrected total & 599 & & & & Error & 1275 & 1579.30 & & \\
\hline \multicolumn{5}{|l|}{ (c) Panel B } & Corrected total & 1349 & & & \\
\hline Velocity & 2 & 498.61 & 7.21 & 0.0088 & \multicolumn{5}{|l|}{ (h) Panel G } \\
\hline Day (Velocity) & 12 & 410.82 & 32.96 & 0.0001 & Velocity & 2 & 249.78 & 3.54 & 0.0619 \\
\hline Surface & 1 & 389.03 & 57.37 & 0.0001 & Day (Velocity) & 12 & 428.31 & 14.79 & 0.0001 \\
\hline Surface $\times$ Velocity & 2 & 60.02 & 4.23 & 0.0406 & Surface & 4 & 5685.50 & 262.03 & 0.0001 \\
\hline Surface $\times$ Day (Velocity) & 12 & 70.91 & 5.69 & 0.0001 & Surface $\times$ Velocity & 8 & 76.18 & 1.76 & 0.1098 \\
\hline Error & 870 & 903.68 & & & Surface $\times$ Day (Velocity) & 48 & 260.38 & 2.27 & 0.0001 \\
\hline Corrected total & 899 & & & & Error & 1275 & 3041.67 & & \\
\hline \multicolumn{5}{|l|}{ (d) Panel C } & Corrected total & 1349 & & & \\
\hline Velocity & 2 & 609.82 & 12.68 & 0.0011 & \multicolumn{5}{|l|}{ (i) Panel H } \\
\hline Day (Velocity) & 12 & 288.60 & 18.80 & 0.0001 & Velocity & 2 & 727.85 & 13.87 & 0.0008 \\
\hline Surface & 1 & 1021.99 & 269.74 & 0.0001 & Day (Velocity) & 12 & 314.89 & 23.64 & 0.0001 \\
\hline Surface $\times$ Velocity & 2 & 80.42 & 10.61 & 0.0022 & Surface & 11 & 11823.78 & 427.92 & 0.0001 \\
\hline Surface $\times$ Day $($ Velocity $)$ & 12 & 45.47 & 2.96 & 0.0005 & Surface $\times$ Velocity & 22 & 373.27 & 6.75 & 0.0001 \\
\hline Error & 870 & 1112.85 & & & Surface $\times$ Day (Velocity) & ) 132 & 331.57 & 2.26 & 0.0001 \\
\hline Corrected total & 899 & & & & Error & 1845 & 2048.44 & & \\
\hline \multicolumn{5}{|l|}{ (e) Panel D } & Corrected Total & 2024 & & & \\
\hline Velocity & 2 & 109.90 & 2.78 & 0.1020 & \multicolumn{5}{|c|}{ (j) Panel H (Placopecten magellanicus) } \\
\hline Day (Velocity) & 12 & 237.36 & 20.23 & 0.0001 & Velocity & 2 & 21.70 & 2.01 & 0.1893 \\
\hline Surface & 1 & 1132.90 & 663.88 & 0.0001 & Day (Velocity) & 9 & 48.53 & 4.74 & 0.0001 \\
\hline Surface $\times$ Velocity & 2 & 7.72 & 2.26 & 0.1467 & Surface & 11 & 546.44 & 43.69 & 0.0001 \\
\hline Surface $\times$ Day $($ Velocity $)$ & 12 & 20.48 & 1.75 & 0.0532 & Surface $\times$ Velocity & 22 & 57.54 & 2.30 & 0.0009 \\
\hline Error & 870 & 850.60 & & & Error & 366 & 409.37 & & \\
\hline Corrected total & 899 & & & & Corrected total & 404 & & & \\
\hline
\end{tabular}

had a density roughly an order of magnitude higher than that of the upper side (Fig 4, panel $H$, types of surface $26 \mathrm{a}$ and $26 \mathrm{~b}$ ).

For vertical $\left(90^{\circ}\right)$ crevices on 3 rd and 4 th order complexity panels, both 10 and $100 \mathrm{~mm}$ crevices showed the same trends in particle density seen in the simpler, 2nd order complexity panels; particle density was always lower inside than outside of crevices (Table 5). Vertical $\left(90^{\circ}\right)$ crevices of $1 \mathrm{~mm}$, however, did not follow the pattern observed for the 2nd order complexity panel of highest density within crevices. Rather, density did not differ between the inside and outside of crevices when they were nested within $10 \mathrm{~mm}$ crevices (Table 4, Fig. 5 panels E, 10 and 11a).
Table 3. Summary of LS Means multiple comparison tests on density of particles; horizontal bars connect means that were not significantly different. Means used for LS Means tests were from transformed data $\left(x^{0.66}\right)$. Significance level was adjusted to 0.0018 (Bonferroni's correction). Type of panels were ranked in increasing order of density of inert particles on panels. Type of panel A is of the first order of complexity, types of panel $B, C$ and $D$ are of the second order, types of panels $E_{r}$

$F$ and $G$ are of the third and type of panel $H$ is of the fourth

\begin{tabular}{llllllllll|}
$3 \mathrm{~cm} \mathrm{~s}^{-1}$ & & G & H & D & F & E & C & A & B \\
$5 \mathrm{~cm} \mathrm{~s}^{-1}$ & G & H & $\bar{D}$ & E & F & C & A & B \\
$10 \mathrm{~cm} \mathrm{~s}^{-1}$ & H & G & C & D & F & E & A & B \\
\hline
\end{tabular}


Table 4. Summary of LS Means multiple comparison tests on density of particles among types of surfaces at all flow velocities and types of panels. Horizontal bars connect means that were not significantly different. Means used for LS Means tests were on transformed data $\left(x^{0.66}\right)$. Significance level was adjusted to 0.005 on types of panels $E, F$ and $G$ and to 0.0008 on type of panel $H$ (Bonferroni's correction). Types of surfaces were ranked in increasing order of density of inert particles

\begin{tabular}{|c|c|c|c|c|c|c|c|c|c|c|c|c|c|c|c|c|c|c|}
\hline \multirow[b]{2}{*}{$3 \mathrm{~cm} \mathrm{~s}^{-1}$} & \multirow{2}{*}{$\begin{array}{c}B \\
2<3\end{array}$} & \multirow{2}{*}{$\frac{C}{5<4}$} & \multirow{2}{*}{\multicolumn{2}{|c|}{$\begin{array}{c}\mathrm{D} \\
7<6\end{array}$}} & \multicolumn{5}{|c|}{ E } & \multicolumn{4}{|c|}{$F$} & \multicolumn{5}{|c|}{$\mathrm{G}$} \\
\hline & & & & & & $10 \quad 11 a$ & a $11 b$ & 9 & 8 & $1415 a$ & $15 b$ & 12 & 13 & $19 a$ & $19 b$ & 18 & 17 & 16 \\
\hline $5 \mathrm{~cm} \mathrm{~s}^{-1}$ & $2<3$ & $5<4$ & & $7<6$ & & $10 \quad 11 \mathrm{a}$ & a $11 b$ & 9 & 8 & $14 \quad 15 \mathrm{a}$ & 12 & $15 b$ & 13 & $19 a$ & $19 b$ & 18 & 17 & 16 \\
\hline $10 \mathrm{~cm} \mathrm{~s}^{-1}$ & $2<3$ & $5<4$ & & $7<6$ & & 1011 a & a $11 b$ & 8 & 9 & $14 \quad 15 \mathrm{a}$ & 12 & $15 b$ & 13 & $19 a$ & 18 & 17 & $19 b$ & 16 \\
\hline & & & & & & $\mathrm{H}$ & & & & & & & & & & & & \\
\hline $3 \mathrm{~cm} \mathrm{~s}^{-1}$ & $27 a \quad 26 a$ & 22 & $23 a$ & $25 a$ & 24 & $23 b$ & $25 b$ & $27 b$ & $26 b$ & 20 & & & & & & & & \\
\hline $5 \mathrm{~cm} \mathrm{~s}^{-1}$ & $27 a \quad 26 a$ & $25 a$ & 22 & $23 a$ & 24 & $23 \mathrm{~b}$ & $25 b$ & $27 \mathrm{~b}$ & 21 & $26 b \quad 20$ & & & & & & & & \\
\hline $10 \mathrm{~cm} \mathrm{~s}^{-1}$ & $27 \mathrm{a} \quad 26 \mathrm{a}$ & 22 & 24 & $23 a$ & $25 a$ & $23 b$ & $25 b$ & $26 \mathrm{~b}$ & 20 & $27 b \quad 21$ & & & & & & & & \\
\hline
\end{tabular}

Fig. 4. Density of inert particles in $200 \mathrm{~mm}^{2}$ quadrats $( \pm S E)$ on all types of surfaces for every type of panel $(A$ to $H$ ). Flow velocity: $\square=0.03, \square=0.05, \square=0.10 \mathrm{~m} \mathrm{~s}^{-1}$, respectively. Letters above histograms indicate means that are not significantly difforent botwoon flow velocities. Since velocity had no effect on particle density for panels $D, E$ and $G$, no a posteriori tests were carried out
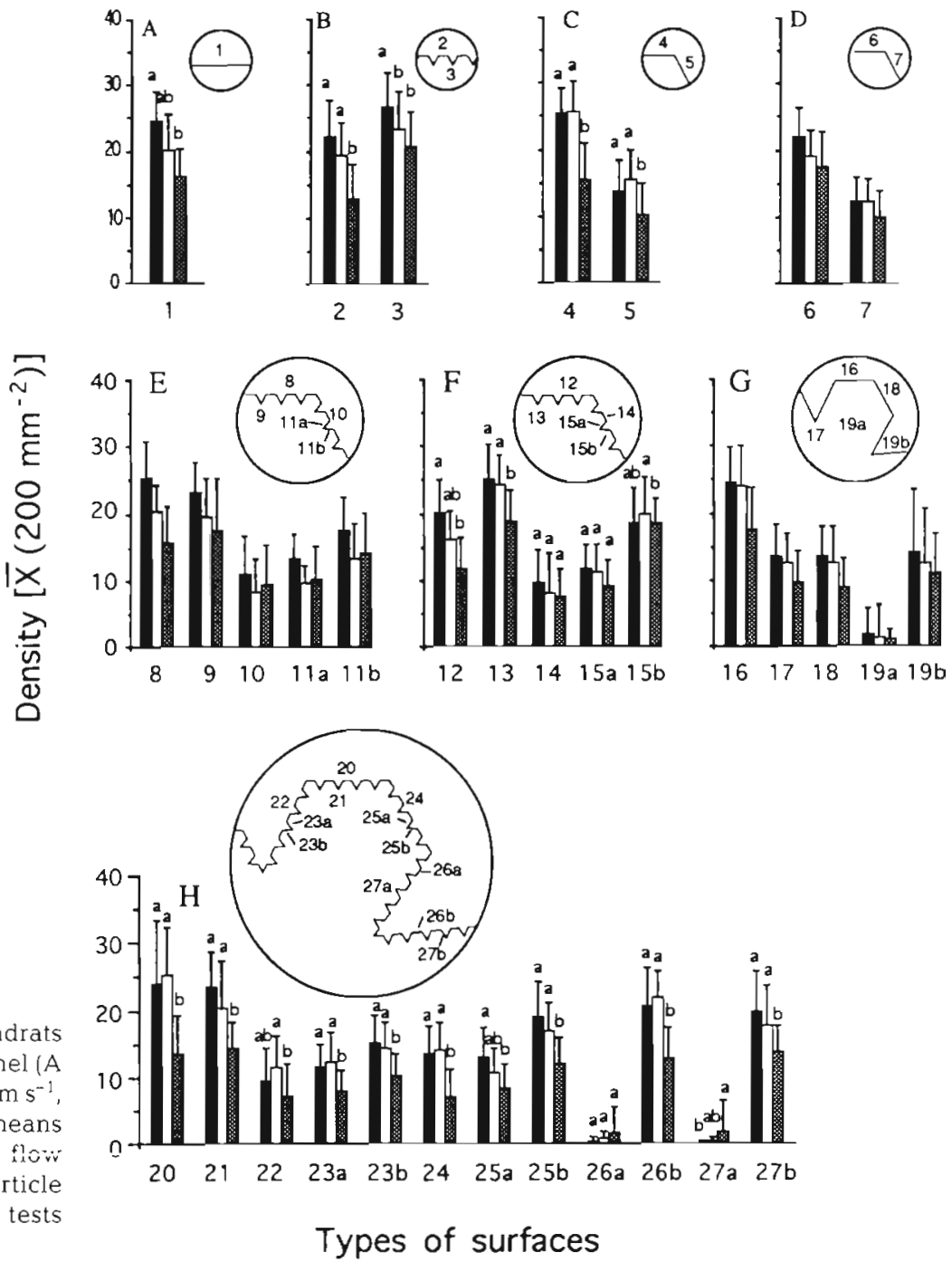
Table 5. Summary of LS Means multiple comparison tests on density of particles among types of surfaces at 10 and 100 mm scales at every flow velocitiy for types of panels $E, F, G$ and $H$. Horizontal bars connect means that are not significantly different. Means used for LS Means tests were transformed data $\left(x^{0.66}\right)$. Significance level was adjusted to 0.005 on type of panel Hat the $10 \mathrm{~mm}$ scale (Bonferroni's correction). Groups of types of surfaces are ranked in increasing order of number of inert particles

\begin{tabular}{|c|c|c|c|}
\hline & $\mathrm{E}(10 \mathrm{~mm})$ & $\mathrm{F}(100 \mathrm{~mm})$ & $\mathrm{G}(100 \mathrm{~mm})$ \\
\hline $\begin{array}{l}3 \mathrm{~cm} \mathrm{~s}^{-1} \\
5 \mathrm{~cm} \mathrm{~s}^{-1} \\
10 \mathrm{~cm} \mathrm{~s}^{-1}\end{array}$ & $\begin{array}{l}(10-11)<(8-9) \\
(10-11)<(8-9) \\
(10-11)<(8-9)\end{array}$ & $\begin{array}{l}(14-15)<(12-13) \\
(14-15)<(12-13) \\
(14-15)<(12-13)\end{array}$ & $\begin{array}{l}(18-19)<(16-17) \\
(18-19)<(16-17) \\
(18-19)<(16-17)\end{array}$ \\
\hline & \multicolumn{2}{|r|}{$\mathrm{H}(10 \mathrm{~mm})$} & $\mathrm{H}(100 \mathrm{~mm})$ \\
\hline $\begin{array}{l}3 \mathrm{~cm} \mathrm{~s}^{-1} \\
5 \mathrm{~cm} \mathrm{~s}^{-1}\end{array}$ & $\begin{array}{l}(26 a-27 a)<(22-23) \\
(26 a-27 a)<(22-23)\end{array}$ & $\begin{aligned}< & (24-25)<(26 b-27 b)<(20-21) \\
(24-25) & <(26 b-27 b) \quad(20-21)\end{aligned}$ & $\begin{array}{l}(24-25-26-27)<(20-21-22-23) \\
(24-25-26-27)<(20-21-22-23)\end{array}$ \\
\hline $10 \mathrm{~cm} \mathrm{~s}^{-1}$ & $(26 a-27 a)<(22-23)$ & $(24-25)<(26 b-27 b) \quad(20-21)$ & $(24-25-26-27)<(20-21-22-23)$ \\
\hline
\end{tabular}

In summary, density was higher within $1 \mathrm{~mm}$ crevices than on adjacent smooth surfaces while the converse was true of 10 and $100 \mathrm{~mm}$ crevices. On panels of 3rd and 4 th order complexity, the density of particles was higher on the lower side of inclined $\left(+30^{\circ}\right)$ crevices while no differences between sides were observed on panels of 2 nd order complexity.

Multiple sign tests were performed to examine the null hypothesis (uniform distribution of particles), regardless of the presence of crevices. In 16 out of 18 tests, $1 \mathrm{~mm}$ crevices collected significantly more particles than expected whereas only the inclined $\left(-30^{\circ}\right)$ $1 \mathrm{~mm}$ crevices collected less. The 10 and $100 \mathrm{~mm}$ crevices also collected more particles than expected, but not as often as $1 \mathrm{~mm}$ crevices. Fourteen out of thirty $10 \mathrm{~mm}$ crevices and seven out of twelve $100 \mathrm{~mm}$ crevices collected significantly more particles than expected. On the upper side of the $+30^{\circ}, 10 \mathrm{~mm}$ crevices collected significantly fewer particles than expected.
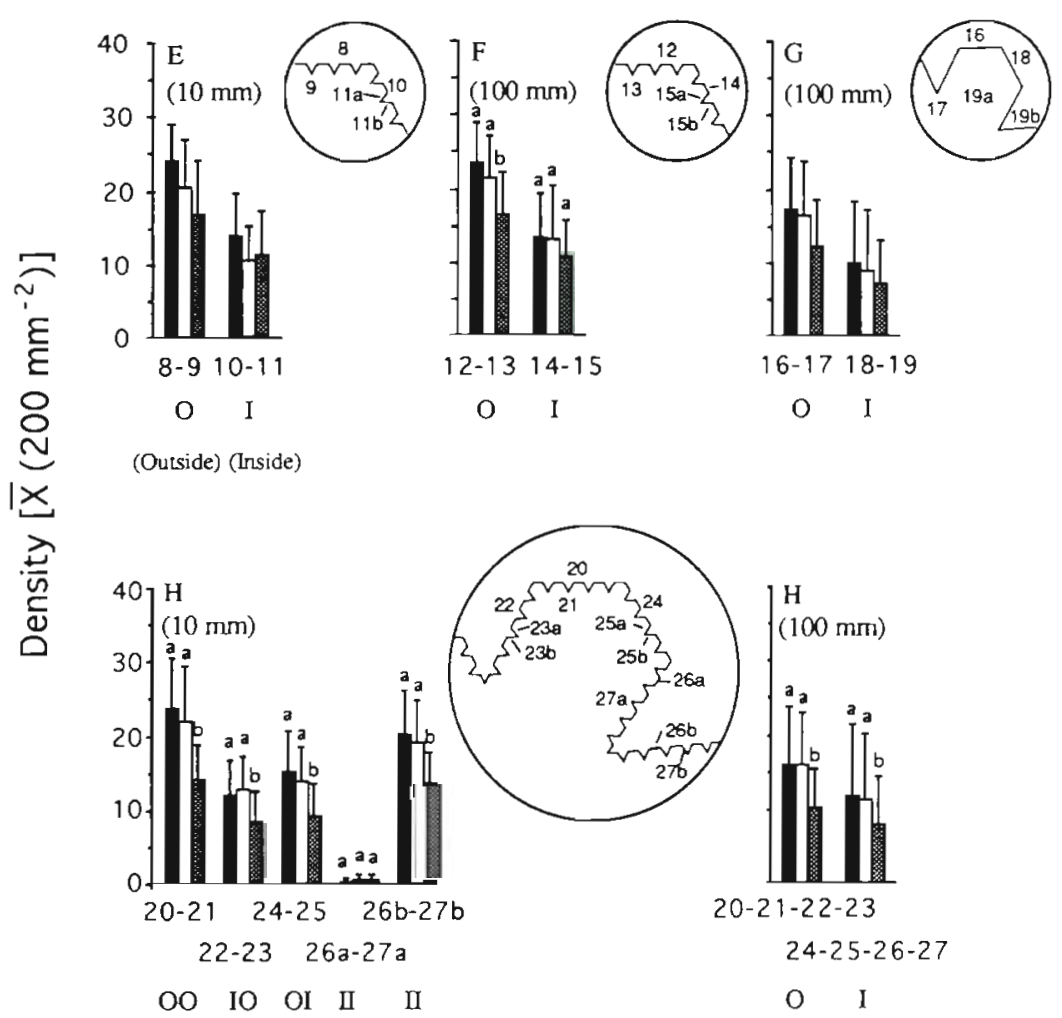

Types of surfaces

Fig. 5. Density of inert particles in $200 \mathrm{~mm}^{2}$ quadrats $(+\mathrm{SE})$ on all types of surfaces and scales (10 and $100 \mathrm{~mm}$ ) of observation for panels $E, F, G$ and $H$. Flow velocity: $\square=0.03$, $\square=0.05, \square=0.10 \mathrm{~m} \mathrm{~s}^{-1}$, respectively. Letters above histograms indicate means that are not significantly different between flow velocities. Since velocity had no effect on particle density for panels $E$ and $G$, no a posterion tests were carried out. For panel $E$ to $G, O$ : outside, I: inside. For panel $H$ at $10 \mathrm{~mm}$, types of surfaces are; OO: outside 10 and $100 \mathrm{~mm}$ crevices, IO: inside $10 \mathrm{~mm}$ but outside $100 \mathrm{~mm}$ crevices, OI: outside $10 \mathrm{~mm}$ but inside $100 \mathrm{~mm}$ crevices, II: inside 10 and $100 \mathrm{~mm}$ crevices 


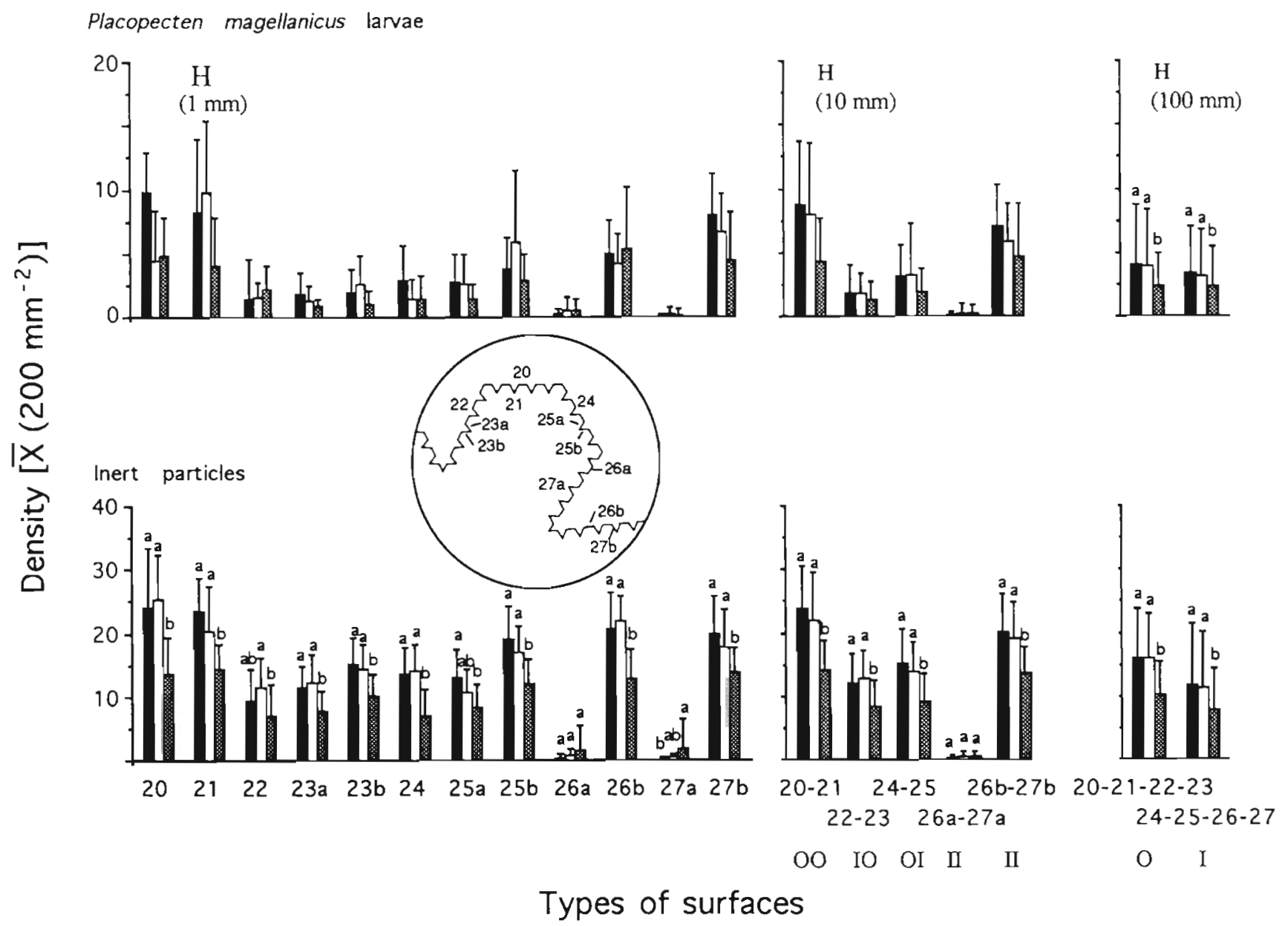

Fig. 6. Density of preserved larvae and inert particles in quadrats ( \pm SE) for every type of surface and scale (1, 10, $100 \mathrm{~mm}$ ) of observation on panel $\mathrm{H}$. Flow velocity: $\square=0.03, \square=0.05, \square=0.10 \mathrm{~m} \mathrm{~s}^{-1}$, respectively. Letters above histograms indicate means that are not significantly different between flow velocities. For more details, see Fig. 5

\section{Passive larval accumulation}

Dead larvae distribution differed significantly among surface types on panel type $\mathrm{H}$ (Table $2 \mathrm{j}$ ). On a scale of $1 \mathrm{~mm}$, higher densities of larvae were generally observed in vertical crevices and on the lower part of crevices inclined at $+30^{\circ}$ compared to other surface types (Table 6, Fig. 6). On a $10 \mathrm{~mm}$ scale, the lower side of the $+30^{\circ}$ crevices had higher densities than that of the upper side and no difference was observed on a $100 \mathrm{~mm}$ scale (Table 6). Density of larvae did not differ among flow velocities (Table 2 j, Fig. 6).

Kendall's coefficient of concordance between distribution patterns of larvae and inert particles at $3 \mathrm{~cm} \mathrm{~s}^{-1}$ was 0.97 , indicating significant concordance $(p<0.05)$. The coefficients of concordance between distribution patierns of İrvae andi inert particies at 5 and $10 \mathrm{~cm} \mathrm{~s}^{-i}$ were high (0.91 and 0.91, respectively), but not significant at 0.05 .

\section{DISCUSSION}

Influence of scales of heterogeneity

In general, particle density was higher (by - 29\%) inside $1 \mathrm{~mm}$ crevices than on adjacent smooth surfaces. In contrast, particle density was lower (by $\sim 40 \%$ ) inside 10 and $100 \mathrm{~mm}$ crevices compared to adjacent smooth surfaces. This indicates that particle collection was enhanced by small-scale heterogeneity. These differences due to the scale of heterogeneity might be explained by hydrodynamic processes.

The density of particles in 10 and $100 \mathrm{~mm}$ crevices was $40 \%$ lower than the density of particles on adjacent smooth surfaces. Given that the crevices have a TSA twice that of flat surfaces, the a prioriprediction is that the density of particles in crevices should be half that of flat surfaces, if particles fall uniformly over the panel surface. However, if turbulence or advection toward the 
Table 6. Summary of LS Means multiple comparison tests on number of preserved larvae among types of surfaces at scales of 1,10 and $100 \mathrm{~mm}$ for every flow velocity on panel $H$. Horizontal bars connect means that were not significantly different. Means used for LS Means tests are transformed data $\left(x^{0.66}\right)$. Significance levels were adjusted to 0.0008 and 0.005 at 1 and $10 \mathrm{~mm}$ scales respectively (Bonferroni's correction). Types of surfaces $(1 \mathrm{~mm})$ and groups of types of surfaces (10 and $100 \mathrm{~mm}$ ) are ranked in increasing order of number of inert partıcles

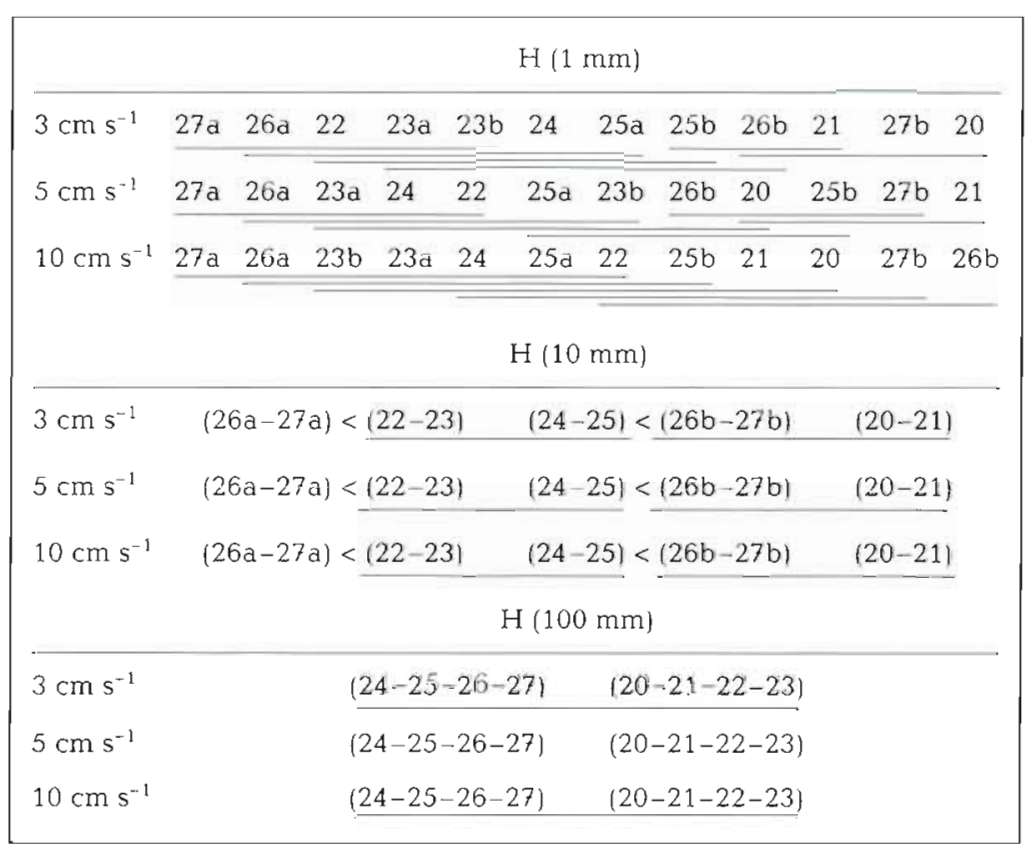

The flow velocity also had an effect on particle density. In general, higher densities were collected at lower velocities, 3 and $5 \mathrm{~cm} \mathrm{~s}^{-1}$, compared to $10 \mathrm{~cm} \mathrm{~s}^{-1}$ As described before, the experiments were conducted near the lower limit of turbulence, so the particles may have a tendency to settle at low velocities.

\section{Infiluence of complexity}

The increased density of particles in $1 \mathrm{~mm}$ crevices was detected inside large crevices. The particle density inside $1 \mathrm{~mm}$ crevices was limited by the number of particles entering the larger crevices. This indicates that the hydrodynamic processes occuring on a large scale $(10$ and $100 \mathrm{~mm}$ ) influenced the outcome on a smaller scale (1 $\mathrm{mm})$.

\section{Particle versus larval settlement}

The experiments with preserved larvae were carried out in order to examine whether the PVC particles used simulated passive larval movement. Kendall's coefficient of concordance $(W)$,

panel was enhanced by substratum heterogeneity, the density of particles inside would be enhanced. The $1 \mathrm{~mm}$ crevices collected significantly more particles than expected indicating that substratum heterogeneity had an influence on hydrodynamic processes which in turn resulted in increased particle collection within these crevices. The 10 and $100 \mathrm{~mm}$ crevices collected significantly more particles than expected in only half of the situations indicating that substratum heterogeneity had less influence on hydrodynamical processes and particle collection at these scales.

Our results may be explained by 2 mechanisms. The apparent scale-dependent collection of particles can be linked to average roughness heights (see Table 1). We observe that $1 \mathrm{~mm}$ crevices at every flow velocity have an average roughness height below or equal to 5 , the upper limit for smooth regime. In the smooth regime, the laminar sublayer is larger than the average roughness (crevice) height, and particles within the sublayer have a strong tendency to fall. Furthermore, the values of average roughness heights for $10 \mathrm{~mm}$ crevices all fall into the transition regime (between 5 and 70). The size of the laminar sublayer relative to the one of the crevices does not allow the particles to fall anymore. varies from 0 to 1,0 indicating no concordance and 1 perfect concordance. Significant concordance $(W>$ $0.95)$ was observed between larval and inert particle collection at a flow velocity of $3 \mathrm{~cm} \mathrm{~s}^{-1}$ (Kendall's $W=$ 0.97 ) but concordance decreased with flow velocities of 5 and $10 \mathrm{~cm} \mathrm{~s}^{-1}(0.90$ and 0.91 , respectively). These results indicated that the PVC particles 'behaved' as simulated larvae for flow velocities used in the experiments.

\section{Comparisons between field and flume distribution}

The patterns of inert PVC particles and of dead larvae accumulating on laboratory panels with $100 \mathrm{~mm}$ crevices (panel D) were similar to those found using identical panels for Mytilus edulis, Hiatella arctica and Obelia longissima in the field (Bourget et al. 1994). Panels B or C, with 1 or 10 mm crevices, had a higher abundance of larvae in the field, compared to inert particles in the present study.

The combination of different scales of heterogeneity resulted in different patterns of distribution for larvae in the field and particles in the laboratory. Results from the field study showed that the combination of scales 
had little effect on bivalve abundance during early colonization, whereas laboratory results showed that density of particles decreased with increasing complexity.

By comparing the settlement patterns of Balanus sp. and Tubularia crocea larvae on silicon-treated panels and untreated panels, Lemire \& Bourget (1996) suggested that larvae are (1) capable of short distance movements prior to settlement, and (2) capable of movements on the substratum after initial contact. The differences between the patterns of distributions of particles seen in laboratory study and those of larvae in the field (Bourget et al. 1994) support this suggestion.

The results presented in this study apply to hydraulically smooth flow. The hydrodynamical conditions encountered in the field range from hydrodynamically smooth to rough even including supercritical flow. All these flow conditions will likely be encountered by most littoral organisms during their lifespan. The panels used for the experiments are representative of the rocky littoral sites in the St. Lawrence estuary, Canada, which feature crevices of varying sizes and complexity (see Bergeron \& Bourget 1986).

The results show that heterogeneity $(1,10$ and $100 \mathrm{~mm}$ ) influenced particle distribution and that the patterns observed were modified with current velocity. The differences observed between larval distributions in the field and particles in the laboratory could be due to movements of larvae on the substrata, avoidance of the substrata by the larvae or differential mortality. Many studies have also suggested that larval distribution resulted from a combination of passive deposition followed by active exploration (Mullineaux \& Butman 1991, Walters 1992, Mullineaux \& Garland 1993). Further studies with larvae in flumes should be carried out to fully understand the detailed mechanisms involved in larval settlement on complex substrata.

Acknowledgements. This manuscript is a contribution to the program of GIROQ (Groupe Interuniversitaire de Recherches Océanographique du Québec). The work was supported by grants from NSERC and FCAR to E.B. and a FCAR scholarship to Y.G. We thank M. Bégin, G. Coté, M. Harvey, L. Lapointe, M. Pouliot, P. Pelletier and $G$. Verret for their help in the laboratory. We also thank Drs M. Fréchette, M. Harvey, $J$. Larochelle and B. Boudreau for their discussions. Drs M. Claereboudt, M. Harvey, G. Miron and C. McKindsey, C. Lovejoy and 1 anonymous referee critically reviewed the manuscript and provided many linguistic improvements. G. Plante helped with particle tracer photographs. G. Daigle assisted with the statistical analysis and validated every test.

\section{LITERATURE CITED}

Bergeron P, Bourget E (1986) Shore topogranhy and apatial partitionning of crevice refuges by sessile epibenthos in an ice disturbed environnment. Mar Ecol Prog Ser 28: $129-145$
Bourget E (1988) Barnacle larval settlement: the perception of cues at different spatial scales. In: Chelazzi $G$, Vannini $M$ (eds) Behavioral adaptations to intertidal life. Plenum Press, New York p 153-172

Bourget E, De Guise J, Daigle G (1994) Scales of substratum heterogeneity, structural complexity, and the early establishment of a marine epibenthic community. J Exp Mar Biol Ecol 181:31-51

Brault S, Bourget E (1985) Structural changes in estuarine subtidal epibenthic community: biotic and physical causes. Mar Ecol Prog Ser 21:63-73

Chabot R, Bourget E (1988) Influence of substratum heterogeneity and settled barnacle density on the settlement of cyprid larvae. Mar Biol 97:45-56

Conover WJ (1980) Practical nonparametric statistics, 2nd edn. John Wiley \& Sons, New York

Crisp DJ (1974) Factors influencing the settlement of marine invertebrate larvae In: Grant PT, Mackie AM (eds) Chemoreception in marine organisms. Academic Press, London, p $177-265$

Gaines S, Brown S, Roughgarden J (1985) Spatial variations in larval concentrations as a cause of spatial variation in settlement for the barnacle, Balanus glandula. Oecologia 67:267-272

Harvey $M$, Bourget $E$, Ingram RG (1995) Experimental evidence of passive accumulation of bivalve larvae on filamentous epibenthic structures. Limnol Oceanogr 40: $94-104$

Havenhand JH, Svane I (1991) Roles of hydrodynamics and larval behaviour in determining spatial aggregation in the tunicate Ciona intestinalis. Mar Ecol Prog Ser 68:271-276

Jensen RA, Morse DE (1984) Intraspecific facilitation of larval recruitment: gregarious settlement of the polychaete Phragmatopoma californica (Fewkes). J Exp Mar Biol Eco] 83:107-126

Kirchmann D, Graham S, Reish D, Mitchell R (1982) Bacteria induce settlement and metamorphosis of Janua (Dexiospira) brasiliensis Grube (Polychaeta: Spirorbidae). J Exp Mar Biol Ecol 56:153-163

Kirk RE (1982) Experimental design: procedures for the behavioral sciences. Brooks/Cole Publishing Company, Pacific Grove

Lemire M, Bourget E (1996) Substratum heterogeneity and complexity influence micro-habitat selection of Balanus sp. and Tubularia crocea larvae. Mar Ecol Prog Ser 135: $77-87$

Le Tourneux F, Bourget E (1988) Importance of physical and brological settlement cues used at different spatial scales by the larvae of Semibalanus balanoides. Mar Biol 97: $57-66$

Lindegarth M, Jonsson PR, André C (1991) Fluorescent microparticles: a new way of vizualizing sedimentation and larval settlement. Limnol Oceanogr 36:1471-1476

Mihm JW, Banta WC, Loeb Gl (1981) Effects of adsorbed organic and primary fouling films on bryozoan settlement. J Exp Mar Biol Ecol 54:167-170

Milliken GA, Johnson DE (1992) Analysis of messy data. Van Nostrand Reinhold, New York

Montgomery DC (1991) Design and analysis of experiments, 3rd edn. John Wiley \& Sons, New York

Mullineaux LS, Butman CA. (1990) Recruitment of benthic encrusting invertebrates in boundary-layer flows: a deepwater experiment on Cross Seamount. Limnol Oceanogr $35: 409-423$

Mullineaux LS, Butman CA (1991) Initial contact, exploration and attachment of barnacle: (Balanus amphitrite) cyprids settling in flow. Mar Biol 110:93-103 
Mullineaux LS, Garland ED (1993) Larval recruitment in response to manipulated field flows. Mar B1ol 116:667-683

Pawlik JR, Butman CA (1993) Settlement of marine tube worms as a function of current velocity: interacting effects of hydrodynamics and behaviour. Limnol Oceanogr 38: $1730-1740$

Rittschof D, Branscomb ES, Costlow JD (1984) Settlement and behaviour in relation to flow and surface in larval barnacles, Balanus amphitrite Darwin. J Exp Mar Biol Ecol 82:131-146

Schlichting $H$ (1962) Boundary layer theory. McGraw-Hill, New York

This article was submitted to the editor
Snelgrove PVR, Butman CA, Grassle JP (1993) Hydrodynamic enhancement of larval settlement in the bivalve Mullinia lateralis (Say) and the polychaete Capitella sp. I in microdepositionnal environments. J Exp Mar Biol Ecol 168: $71-109$

Walters LJ (1992) Field settlement locations on subtidal marine hard substrata: is active larval exploration involved? Limnol Oceanogr 37:1101-1107

Wethey DS (1984) Spatial pattern in barnacle settlement: day to day changes during the settlement season. J Mar Biol Ass UK 64:687-698

Manuscript first received: September 15, 1995

Revised version accepted: November 27, 1995 